\title{
AYURVEDA AND CHINESE MEDICINE
}

\author{
Prof. LEUNG Ping Chung1, 2 \\ ${ }^{1}$ Institute of Chinese Medicine, The Chinese University of Hong Kong, Hong Kong \\ ${ }^{2}$ State Key Laboratory of Research on Bioactivities and Clinical Applications of Medicinal Plants \\ (The Chinese University of Hong Kong) \\ kfcheng@cuhk.edu.hk
}

Received: 18 December 2020; Accepted: 27 December 2020; Published: 31 December 2020

\begin{abstract}
Traditional Indian Medicine Ayurveda and Traditional Chinese Medicine are the oldest systems of health care: the former mastering 5000 years of documentations, the latter at least 3000 years. All ancient medicine has strong philosophical background and management varieties related to manual activities. Indeed Ayurveda is strongly linked with Yoga and Traditional Chinese medicine with activities related to Martial art and Acupuncture. It is a common belief that in the United States, before Yoga was popularly practiced, Ayurveda was hardly known. As for Chinese medicine, acupuncture has been taken as the hawmark. Medicinal herbs which actually form the main core of treatment in Chinese medicine, was virtually unknown outside China.

Actually, there is a broad background behind which the emerging popularity gradually develops. Firstly, there is the disillusion about the exaggerated trust over modern medicine. But it is becoming clear that degenerative diseases and in some other situations like cancer treatment could be so complicated that causative factors are multiple, unclear and would remain obscure. Trying to remove or control the unknown factors cannot rely on known targets. Modern medicine, in the current context, therefore, can not be perfect. Secondly, self-care is becoming more and more important.

This paper recommends a methodology of research on the traditional practice of clinical care with the aim of achieving biological and clinical evidences, when herbal items are used. Suggestions are also given for a closer collaboration between the two traditional practices with different origins

Keywords- Ayurveda; Traditional Chinese Medicine; modern medicine; health care.
\end{abstract}

\section{INTRODUCTION}

According to the World Health Organization (WHO), $80 \%$ of World's population still rely on traditional medicine related to their culture and native area for their health needs. (1) This of course, is only a relative fact because since over a century ago, modern medicine has been the main force of disease irradication and extension of human longevity. (2) However, Traditional medicine has such a strong cultural link that when people feel that their health is being challenged, they tend to use some traditional remedy before going to the modern clinic. When they get disappointed with modern treatment, they also revert to traditional practice. $(3,4)$

The Academic views trying to explain the firm trust attached to traditional medicine in spite of the contradicting scientific developments may include three main arguments:

1. Specialization and over-specialization in Modern Medicine could be confusing to disease victims and certainly could make the treatment cost unaffordable.

2. Inspite of major advances in the pharmaceutical industry, disappointment in the process of treatment is still common, and

3. The aging population suffers from not one but many degenerative conditions affecting multiple organs, making specific therapy unsatisfactory. $(5,6)$

Traditional medicine offers a general promise of physiological balance and state of holistic harmony which particularly favors disease prevention and the elderlies people.

\section{Asian Traditional Medicine}

When WHO advocates the importance of traditional medicine, in its recent determination to bring it more in line with modern practice. It particularly reviewed the diagnostic aspects of Traditional Chinese Medicine in the attempt to make the specific terms more acceptable to the medical public. (7)

Since Traditional Medicine Practices in Asia, from China, India to the Middle East, have their own ways of making diagnosis, describing syndromes and staging of illnesses, it could be expected that apart from endorsing the Traditional Chinese Medicine's "pattern" description which is expected to match with treatment strategy, what follows could be another review to cover other Asian systems of traditional healing. In the Middle East: Iran and Islamic Regions, Traditional Medicine has also remarkable history. It actually inherited the ancient European Hellenistic - Greco - Arabic Medical teachings, thence settled in Persia as Yunani medicine and elsewhere as Islamic or Arabic Medicine. The complexity of Traditional Medicine in the Middle East is therefore comparable to Traditional Chinese Medicine. (8)

The consequences of Industrial Revolution followed by the Development of Science and Technology in Europe had overwhelming influences on Traditional Medicine in the Middle East. Its down-grading was much more rapid and devastating than what happened in India and China. In spite of the very rich collection of records and books, (which are hardly quoted today outside the Middle East) and the practical value international recognition appears totally lost. 
A classical record written in Chinese: "Islamic Treatise of Prescriptions"回回藥方 of the Yuen Dynasty (1260-1368) has demonstrated the close connections between Arabic Islamic District and China since nearly $40 \%$ of documented herbs were imported from the Middle East and Persia. (8) One century later the World-Renowned Encyclopedia on Medicinal herbs 本草綱目 listed some $10 \%$ of herbal items imported from the Middle East and India. (9)

Indian and Chinese Traditional Medicine could have developed around the same period over 3000 years ago with sharing of concepts and medicinal materials unknown to the practitioners. Today, we do find similarities and differences between them when we study their ways of thinking: philosophy of life and health; diagnostic techniques; treatment principles and outcome assessments. $(10,11)$

\section{Ayurveda and Chinese Medicine}

The philosophical basis of both traditional practices is to prolong life and maintenance of wellbeing. (10) The Chinese side stresses the importance of Yin and Yang which refers to balance and harmony. Whether in physiological good health or under pathological conditions, opposing forces presenting as heat or cold, deep or superficial, real or apparent, are keeping the individual in a balanced state, manifested in a spiritual attitude called 'Qi'. $(12,13)$ There is no exactly equivalent line of thoughts in Ayurveda. But the interpretation of the living state has obvious similarities. Indian philosophers believes that everything under the Universe, including the human body is composed of five elements: Wood, Fire, Earth, Metal, Water, and the elements are kept at a balanced state to provide well-being. (14)

Chinese Medicine likewise, respects the same five elements when it defines the interactions between the different physiological functions and related organs. (15) Ayurvedic interpretations of the five elements tend to be more sophisticated in that, not only are they related to different organs under special circumstances, but the loss of balance affects medical management. The spiritual aspects of the individual are very much emphasized. (16)

Thus, management given by Traditional Chinese Medicine practitioners very much depends on the judgement of the lack of balance: deficiency or over-activity. Whereas Ayurveda advocates a more structured identification of problems, followed by a more spiritual orientated management (11)(17), sometimes reaching a religious state.

\section{Current State of Ayurveda and Traditional Chinese Medicine}

People might understand Ayurveda as Yoga, and Traditional Chinese Medicine as Acupuncture, since outside India and China, Yoga training and Acupuncture treatment are indeed hallmarks for either stream. A better way to understand the two most important traditional practices, after identifying their philosophical similarities will be a careful look at their respective situations: from practice, education, commercial activities to research.

\section{Ayurveda (AYUSH)}

The India Government is actively encouraging traditional medical practice. Ayurveda (being the best known Indian Traditional Medicine) has been united with four other related and yet different traditional practices, viz. Unani, Siddha, Sowa Rigpa and Homeopathy to form the consortium AYUSH. The author is unable to obtain the most update statistics but according to data of 2012 the strength of AYUSH in India is impressive. (18). AYUSH hospitals in India amount to $27.5 \%$ of all hospital; providing 58,000 beds which represent $9.7 \%$ of all hospital beds. AYUSH clinicians amount to 720,000 which are equivalent to $43.7 \%$. In the rural areas, community set ups providing AYUSH services are plentiful, well superseding those providing modern services $(51.6 \%$ vs $35.7 \%$ )

It is estimated that there are 25.9 AYUSH hospitals every 10 million people; 0.3 AYUSH clinic per 10,000 people; 0.5 hospital bed per 10,000 people, and 5.9 AYUSH clinicians per 10,000 people. In 2012 , there has been a flourish of new AYUSH hospitals and clinics, amounting to $90 \%$ of the overall new hospitals and $89.8 \%$ of overall new clinics in India. This huge system is providing education, services, industrial support and Research promotions.(19)

\section{Traditional Chinese Medicine}

In China, Traditional Chinese medicine services are widespread. The National Policy, for over half a century, has been insisting on at least $20 \%$ of national resources for health care to be given to traditional Chinese medicine. Regarding infrastructures, over 3000 municipal level hospitals for Chinese medicine have been established. Over 330,000 beds are provided, over 160 specialties are allocated. $90 \%$ of comprehensive hospitals are in possession of special Chinese medicine services. The number of registered Chinese medicine practitioner ranged from 520,000 (certificate) to 237,000 (fully registered). Over 240 millions out-patient visits per year have been recorded. $18.5 \%$ emergency care are provided by traditional practitioners. (Data were those of late last century) (19)

Currently there are 32 Chinese Medicine Universities and 52 Comprehensive Universities offering herbal pharmacology or Chinese medicine courses. The total number of Chinese medicine students is estimated to be around 270,000 while senior respectable Chinese medicine experts are still taking graduates under apprenticeship training.

In spite of the formalization of undergraduate training and the mounting increases in educational resources for traditional Chinese medicine, it has been observed that the general quality of the graduates is apparently down-grading. The problems include: a declining interest on the traditional concepts and philosophy, obsolete teaching methodology and marginalization of traditional classic educational volumes. Students are receiving low-quality Clinical training while their knowledge about medicinal plants and dried herbs are limited. Another obvious threat to young students' pursue on a Chinese medicine practitioner's career exists in the rather narrow pathway of clinical commitment. It is not uncommon to find graduates entering completely different fields. One way to overcome the declining popularity is taking the form of integrated service, combining allopathic and traditional medicine in joint services. In view of the lack of clear division of labour, integration remains stagnant, while the overwhelming authoritative scientific approaches of allopathic medicine would not allow proper sharing of efforts. $(20,21)$ 
Industry involvement in Traditional Chinese Medicine in China has been strong and active.

The strong traditional use of proprietary herbal medicine has helped to maintain a rather prosperous market. Herbal items on sale are usually those handed down since hundreds or thousands of years. Attempts to give modern evidence to their current uses are scanty. Though unusual, innovative new creations are available but not many of them have gone through evidence-based investigations. Clinical trials on new applications are reported, but it is well known that most, if not all, of these trials are of poor qualities. $(22,23)$

Pharmacologists interested at Chinese medicine are following the only research direction of drug discovery. Infrastructures designed for drug development using medicinal plants are plentiful, (over 180) and an estimate of 30,000 pharmacologists are involved. $(24,25)$

Isolated groups are trying to work out scientific supports for the traditional concepts of traditional medicine which are often more philosophical than scientific or technical. As of to-date, little successful results are reported.

The Industrial side of traditional medicine appears to be brighter since the export of herbal medicine and related products have been increasing in the past 20 years at a rate of about $20 \%$ per year. Amidst this optimism, the deteriorating quality of herbs has already emerged as a real threat. The causative factors like environmental pollution, overcultivation, adulterations and poor quality controls, are all contributive. (26)

\section{Innovations on Modernization of Traditional Medicine}

The two Traditional Medicine systems have well stood the challenge of scientific advancements and have kept their luster of practical services. They share common elements of philosophical ideas, while keeping their unique methods of clinical practice. Since both India and China occupy vast territories, they are in command of rich resources of vegitations which are providing them with enormous herbal resources. (27)

Indian and Chinese people are sharing their individual trust and admirations on their individual cultural heritage, they are also sharing an urnest expectation of further development, viz. modernization through which more trust could be generated and greater contributions are expected in the global quest for novel means to supplement problematic areas of health management. $(28,29)$

Modern medicine has been successful in "target therapy", emphasizing on specific treatment against specific targets. The successes are obvious when the target is clear and solitary. Yet, diseases could have multiple causes many of which remain unclear, thus making specific treatment disappointing. Examples of difficult areas are often related to aging, degenerations, chronic diseases and cancer. (10)

It has been the aspirations of clinical scientists to systematically put traditional medicine, particularly their medicinal herbs, into a comprehensive system of clinicalpharmacological research in the attempt to provide effective agents to supplement modern clinical practice. (30)

The following diagram summarizes the research approach. Many specific health supplements have been developed according to this evidence-based approach since two decades ago in Hong Kong. (2)

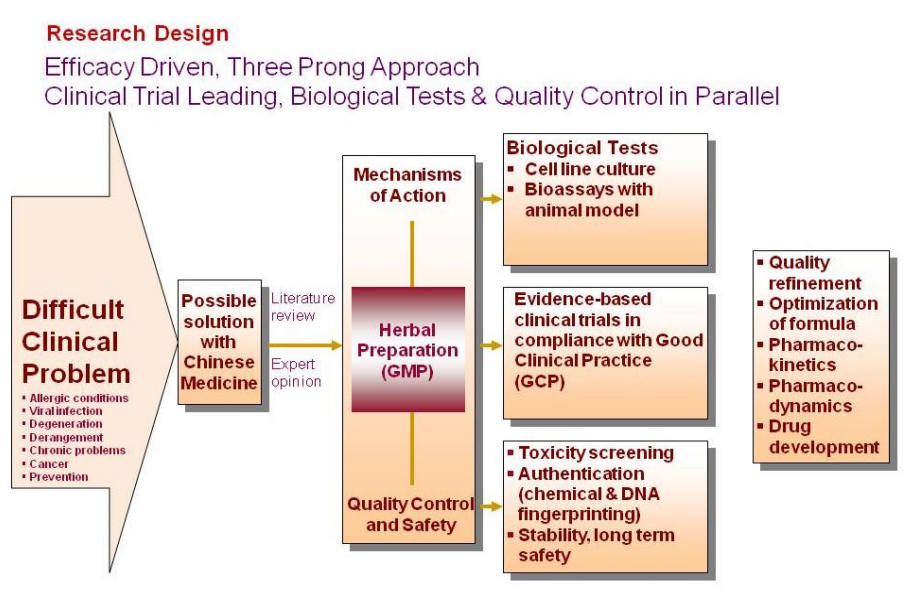

Joint Mission of the Two Asian Traditional Systems

The two Asian Systems of Health and Medical Treatment could jointly discuss about modernization because of the obvious similarities. Both Systems are ancient, with over 3,000 years of age. Both have strong cultural and philosophical background: Ayurveda with Hinduism and Chinese Medicine with Buddhism and Taoism. They have been providing practical services to the people of related regions ever since they are known, throughout their development, and up to to-day.

Both Ayurveda and Chinese Medicine believe in Holism, i.e. taking the human bodily functions as a whole. Totally balanced bodily functions result in harmony and perfect health. The dysfunction of some parts leads to loss of the harmony manifested with different sets of disorders, syndromes and symptoms related to different organs. To remove the symptoms, not only are specific measures targeting towards the symptoms important. Instead, to maintain the harmony of whole body could be of equal significance.

The rich collections of medicinal herbs in Ayurveda and Chinese Medicine would form a vast base for the provision of appropriate agents to supplement deficiencies in modern clinical management. It is appropriate time that the Ayurvedic experience could be shared with the Chinese Tradition and vice versa in the early mission of collaboration, aiming at synergistic effects. (31) It is not going to be a straight forward effort. Both traditional systems are facing similar challenges. (32)

Firstly, the strong cultural adoration has maintained the popularity of the traditional practice, but at the same time, discouraged the traditional practioners to communicate with modern scientists and clinicians. Sticking firmly to old theories and rigid practices have hindered the endorsement of Evidence-Based Research and Practice. This group frankly discredit modernization.

Secondly, clinical and bio-scientists insist on absolute scientific approach of the reductionist stream. They do not believe that traditional medicine can be up-graded to the Evidence-Based level. Their interest on medicinal herbs stays on the Drug Discovery level.

Thirdly, although there are State Policies of integrating traditional and modern medicine, both in China and India, the Traditional Medicine and Modern Medicine, have remained two separate streams. On the clinical side they could be polite 
and respectful to each other, but they choose to stay on their own practice. A new paradigm is required to initiate a genuine state of collaboration. $(19,18)$.

China has just started a new initiative of developing medicinal supplements aiming at specific health needs (including disease targets) using modified traditional herbal formulations, and going along the Evidence-based requirements as have been proposed in Europe and America. $(33,34,35) \quad$ Perhaps this is a practical way of bringing traditional medicine to a higher practical level. (36)

\section{REFERENCES}

[1] World Health Organisation (2002). WHO Traditional Medicine Strategy 2002-2005. WHO, Geneva.

[2] Leung PC (2015). Botanical Products for Medicinal Use. In Comprehensive Guide to Chinese Medicine, World Scientific Publisher, Singapore.

[3] Takakusu J (1956). Observations of Medicine in India and China History of Science in India - Editorial Enterprises, Dehli.

[4] Zhang Y.H., Rose K (1995). An Exploration of the Cultural Roots of Traditional Chinese Medicine. Paradigm Publications, Brooklin, Massachusetts.

[5] Campion EW (1993). Why Unconventional Medicine? New England J Med 328(4) 282-283.

[6] Goldbeck Wood S, Dorozynski A (1996). Complementary Medicine is Booming World Wide. BMJ 313, 131.

[7] World Health Organization WHO 2013. WHO Traditional Medicine Strategy, 2014-2023.

[8] Leung PC. Building a Bridge Between SE Asia and Middle East on the Modernisation of Regional Traditional Medicine China and the World: Ancient and Modern Silk Road, (2018) Vol 1-5. http://qoi.org/10.1142/s259172.

[9] Kong YC., Chan DS (1996). Elucidation of Islamic Drugs in Hui Hui Fang: A Linguistic and Pharmaceutical Approach. Journal of Ethnopharmacology 54, Issues 2-3, November 1996, (2-3), 85-102. https://doi.org/10.1016/S0378-8741(96)01452-3

[10] Leung PC, Panda D (2017). From Ayurveda to Chinese Medicine. World Scientific Publisher, Singapore.

[11] Panda D (2017). Health and Disease in Ayurveda. In "From Ayurveda to Chinese Medicine". World Scientific Publisher, Singapore.

[12] Yi XK (2007). Natural Healing in Chinese Medicine. World Health Digest 4, 269-270.

[13] Macek N., (1984). East Meets West to Balance Immunologic Yin and Yang. JAMA 251(4), 433-441.

[14] Filliozat J (1964). The Classical Doctrine of Indian Medicine. Munshiram Manoharlal Oriental Booksellers \& Publishers, Delhi.

[15] Svoboda R., Lade A (1995). Tao and Dharma-Chinese Medicine and Ayurveda. Lotus Press. WI53181.

[16] Beinfield H., Kovngold E (1991). Between Heaven and Earth: A guide to Chinese Medicine. Ballantine Books, New York.

[17] Heyn B (1987). Ayurvedic Medicine: The Gentle Strength of Indian Healing, Thorsons Publishers, Welling borough.

[18] AYUSH (2015). AYUSH in India. Ministry of Health and Family Welfare, Government of India.

[19] Mukherjee PK, Wahile A (2006). Integrated Approaches Towards drug Development from Ayurveda and Other Indian System of Medicine. J. Ethnopharmacology 103, 25-35.

[20] Xu QY (2001). Medicial Education in China. Proceedings on Health Care, East and West, Moving into the 21st Century, Harvard.

[21] Lee SK (2016). Legislation for Traditional Chinese Medicine. J People's Congress of China 1 (1), 33.

[22] Ministry of Health, People's Republic of China 1995. Traditional Chinese Medicine Services. Ministry of Health, PRC.

[23] Leung PC., Cheng KF., Fong YS (2015). Clinical Trials to Evaluate Chinese Medicine. In Comprehensive Guide to Chinese Medicine. World Scientific Publisher, Singapore.

[24] Tang J., Zhan SY., Ernst E (1999). Review of Randomized Control Trials of Traditional Chinese Medicine. Br. Med J. 319, 160-161.
[25] O’Brieu K (2002). Problems and potentials of Complementary and Alternative Medicine. J. Intern Med., 32, 163-164.

[26] Chinese Herbal Medicine (1998). Shanghai Science and Technology Press, Shanghai.

[27] Mukherjee PK., Rai S; Kumar V., Hyland PJ (2017). Plants of Indian Origin in Drug Discovery. Expert Opin Drug Discov., 2 (5) 633-657.

[28] Takakusu J (1956). Observation of Medicine in India and China. IN "History of Science in India" - Editorial Enterprises, New Dehli.

[29] Watanabe K, Matsuura K., Gao PF etal. Traditional Japanese Kampo Medicine: Clinical Research Between Modern and Traditional Medicine. Evidence based Complementary Alternative Medicine 2011, 51384.

[30] Lau BS., K CH, Leung PC et al (2017). Research and Development of Chinese Medicinal Plants. In "From Ayurveda to Chinese Medicine", World Scientific ........ etc.

[31] Deborath PK., Banerjee S., Debnath P (2015). Ayurveda Opportunities for Developing Safe and Effective Treatment Choices for the Future in Evidence-based Validation of Herbal Medicine, Elsevier, Amsterdam.

[32] Sen S., Chakraborty R., De B (2011). Challenges and Opportunities in the Advancement of Herbal Medicine. India's Position and Role in a Global Context. J. Herb Med 1, 67-75.

[33] Aggett., Antoine Jm., Asp NG (2005). Process for the Assessment of Scientific Support for Claims on Foods (PASSCLAIM). Eur. J. Nutr 44 (1 Suppl), i5-i30.

[34] American Association of Clinical Endocrinologists (AACE) 2003. Medical Guidelines for Clinical Use of Dietary Supplements and Nutraceuticals. Endocrine Practice 9(5) 417-470.

[35] Diplock AT 1999. Scientific Concepts of Functional Foods in EuropeConsensus Document. Br. J Nutr. 81(1), 1-27.

[36] Clydesdal FM (1997). A Proposal for the Establishment of Scientific Criteria for Health Claims for Functional Foods. Nutr Res. 55(12), 413 422. 